\title{
The Association between Intimate Partner Rape and Victimisation from Intimate Partner Controlling Behaviour and Physical Aggression in a Ugandan Sample
}

\author{
Brendah Nakyazze \\ Åbo Akademi University, \\ Finland \\ brendah.nakyazze@abo.fi
}

\author{
Karin Österman \\ Åbo Akademi University, \\ Finland \\ karin.osterman@abo.fi
}

\author{
Kaj Björkqvist \\ Åbo Akademi University, \\ Finland \\ kaj.bjorkqvist@abo.fi
}

\begin{abstract}
The aim of the study was to investigate the relationship between victimisation from intimate partner rape and two types of intimate partner aggression. A questionnaire was completed by 609 females and 420 males in Uganda. The age range was between 16 and 94 years. The mean age was 31.5 (SD 10.9) for females, and 34.4 (SD 11.3) for males. The questionnaire included scales for measuring the frequency of victimisation from intimate parther rape, controlling behaviour, and physical aggression from an intimate partner. Females had been significantly more often victimised from intimate partner physical aggression than males. No significant difference was found between females and males on victimisation from intimate partner controlling behaviour. Victimisation from physical aggression and controlling behaviour from a partner were also highly correlated with each other for both females and males. Respondents who had been more than average victimised from intimate partner rape scored significantly higher than others on victimisation from intimate partner controlling behaviour and intimate partner physical aggression. The association between victimization from intimate parther rape and victimisation from intimate partner controlling behaviour and physical aggression followed the same pattern for females and males.
\end{abstract}

Keywords: Intimate partner rape, intimate partner controlling behaviour, intimate partner physical aggression, sex differences, Uganda.

Received 24 October 2021/Accepted 2I February 2022 @Author all rights reserved

\section{Introduction}

Intimate partner rape is seldom an isolated incident, since it often occurs along with other types of abusive behaviour, such as physical and psychological abuse (Garcia-Moreno, Jansen, Ellsberg, Heise, \& Watts, 2006). When deciding the nature of any type of intimate partner violence, it is worth 
considering the presence or absence of controlling behaviour (Johnson, 2006). Controlling behaviour, just like intimate partner sexual abuse, can take on different forms shaped by cultural norms (Bergen, 1996; Finkelhor \& Yllo, 1985; Russell, 1990), institutional roles (Jenkin, 2000), and personal attributes (Dutton, 2006). Control is achieved through threats, emotional abuse, and physical and sexual abuse (Johnson, 2006). A positive correlation between marital rape and controlling behaviour has been found (Campbell, 1989).

In controlling behaviour, the power motive is often present (Sugarman \& Frankel, 1996). Power and control have also been suggested to be catalysts for most types of intimate partner violence (Johnson, 1995). Controlling behaviour within intimate partner relationships incorporates forms of command, exploitation, and deprivation by a partner in order to force obedience (Stark, 2007). Intimate partner sexual violence including rape is often perceived as an act of misuse of power (Campbell, 1989). For many perpetrators, it is usually an attempt to prove hegemony by exerting control over their partners (Sugarman \& Frankel, 1996). It is a characteristic of husbands who rape their wives to be domineering and to see their wives as mere commodities (Frieze, 1983; Johnson, 1995). Male perpetrators have been found to use intimate partner punitive rape, a masculine response, as a punishment or disciplinary measure in order to implant discipline and force the victim to behave in a way they consider appropriate or right (Rozee, 1993).

For $45.9 \%$ of African American women that were sampled from an American midwestern city (Campbell \& Soeken, 1999), an exposure to both sexual and physical violence has been found (National sex and reproduction research team \& Jenkins, 1994). Studies have shown that intimate partner controlling behaviour, especially among men, increases the likelihood of intimate partner sexual (Gage \& Hutchinson, 2006; Jenkin, 2000) and physical violence (Heise, Ellsberg, \& Gottemoeller, 1999; Johnson, 2000). However, there are also cases where the presence of controlling behaviour is not linked to sexual or physical violence (Anderson, 2008). It has been noted that exposure to intimate partner controlling behaviour increased the likelihood of experiencing intimate partner physical violence (Antai, 20l I). The power and control wheel model suggests that violence is among the control tactics used by abusive partners (Pence \& Paymar, 1993). Research has shown a positive association between intimate partner physical and sexual abuse, and battered women are 
also being raped by their partners (Frieze, 1983; Weiss \& Gupta, 1998). For such victims, intimate partner rape has been found to be accompanied by physical assault and battery, resulting into severe injuries (Khan, Townsend, Sinha, \& Lakhanpal, 1996; Mahoney \& Williams, 1998; Pagelow, 198I) and correspondingly, victimisation from intimate partner physical abuse increases the likelihood of sexual abuse (Coker, Smith, McKeown, \& King, 2000). It was found in a study from an American midwestern city that victims from both physical and sexual intimate partner abuse did not have a proper label for their experience (Campbell \& Soeken, 1999).

The aim of this study was to investigate the interplay between victimisation from intimate partner rape, controlling behaviour, and physical aggression in intimate partner relations in a sample including both female and male victims in Uganda. The study was quantitative and conducted with a questionnaire completed by 609 females and 420 males in Uganda.

\section{Sexual Aggression in the African Context}

Cross-national comparisons have shown victimisation of women to be higher in countries with low social equality between men and women (Yodanis, 2004). According to the United Nations gender equality index, 27 of the 30 most gender unequal countries in the world are in Africa (United Nations Development Programme, 2013). Despite the fact that intimate partner rape is common in many African societies (Russell, 1990), it is still not considered a crime, sex is regarded as an obligation in the context of marriage (Barshis, 1983).

Traditional African cultural norms award men superiority over females, and male perpetrated violence is under certain circumstances endorsed and accepted by both women and men (Mann \& Takyi, 2009); behaviours such as neglect of "wifely duties" are considered punishable by physical violence (Worden \& Carlson, 2005). In a study carried out among rural families in Uganda, $70 \%$ of the men endorsed the use of physical violence against their wives if their wives acted in ways they considered disrespectful and disobedient and remarkably, $90 \%$ of the women in the same study held similar attitudes and believed the use of physical violence by husbands is occasionally called for (Koenig, Lutalo, Zhao, Nalugoda, Wabwire-Mangen, et al., 2003). 
To fully understand the background of intimate partner sexual abuse in Africa, it ought to be decoded against gender roles and family life (Jewkes \& Morrell, 2010). In Ghana for example, men are considered wiser than women, therefore awarded higher positions of authority in society, and the illiteracy level in Ghana is higher among women compared to men (Baokye, 2009). Societies that hold firm views about gender roles usually endorse the use of physical and sexual violence as a means of controlling an intimate partner (Reitzel-Jaffe \& Wolfe, 200I). A study carried out in Ghana revealed the presence of controlling behaviours to be associated with other types of intimate partner abuse (Prospero, Dwumah, \& Ofori-Dua, 2009). In a study from Uganda, it was found that only one percent among the female respondents and two percent among the males reported zero tolerance for intimate partner rape (Nakyazze, Österman, \& Björkqvist, 20I8). It was also found that victimization from sexual abuse, negative psychological concomitants and accepting attitudes towards intimate partner rape were related to a low educational level.

Bronfenbrenner's ecological model supplies a theoretical explanation of the development of power imbalances within patriarchal cultures (Bronfenbrenner, 1974) that work to create a social order, which confirms a male-dominated family structure (Johnson, 1995) where control tends to be asserted with sexual, physical, and psychological aggression (Goodmark, 201 I). African traditional norms and beliefs endorse men's hierarchical positions in sexual relationships, especially in long term cohabitations and marriage (Morrell, Jewkes, \& Lindegger, 20I2). These beliefs are widespread in East Africa where through the practice of a bride price, underaged girls, especially in rural areas, are usually forced into marriages, and women are often denied the liberty to choose their own marriage partners (Ellsberg, Heise, Peña, Agurto, \& Winkvist, 200I). In Tanzania for example, one in four girls who have been raped is forced to marry the perpetrator, thereby exposing her to further sexual abuse in marriage (Williams, McCloskey, \& Larsen, 2008). The patriarchal ideology and well-defined gender roles in most African family structures (Dobash \& Dobash, 1979) set the tone for legitimisation and justification (Galtung, 1990) of intimate partner sexual abuse, especially marital rape (Boakye, 2009). Such is the case with intimate partner normative rape, which is justified and supported by socialcultural and traditions norms (Rozee, 1993). 


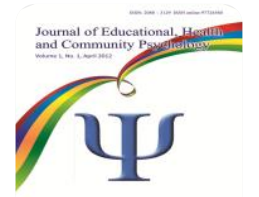

\section{Gender Symmetry in Perpetration of Intimate Partner Sexual Violence}

Gender symmetry in the domestic violence literature has yielded competing models and is a topic of acrimonious debate (Rennison \& Welchans, 2000). Most of the research on intimate partner abuse carried out in the past decades considered it to be only male-perpetrated, and the emphasis has been on female victims (Tjadens \& Thoennes, 2000). Only a hand full of studies were directed towards male victims of intimate partner violence (Steinmetz, 1977-78). However, recent studies point to a gender symmetry in the perpetration of intimate partner violence (Archer, 2000; Fiebert, 1997; Straus, 2010). It has also been presented as bidirectional (Straus \& Ramirez, 2007).

Archer (2018) has suggested a revised gender symmetry theory, according to which gender symmetry holds only for low intensity aggression, while as far as high intensity aggression is concerned, males are perpetrators to a higher degree than females. Furthermore, Archer suggested that gender symmetry should be expected to be found mainly in modern Western nations. As a consequence, in developing countries with a patriarchal society structure, such as countries in Africa, gender symmetry should not be expected to occur. In contrast to this suggestion by Archer, it was found, in a study from South Sudan, that males reported being victimised from both physical and verbal intimate partner aggression to a greater extent than females (Ndoromo, Österman, \& Björkqvist, 20I7). This finding runs counter to the suggestion that gender symmetry theory would not hold in a patriarchal, developing country. The same phenomenon was observed in a study from Ghana, where men also were more victimised by low intensity intimate partner aggression than women (Darko, Björkqvist, \& Österman, 2019). Males scored higher than females on being victimised by their partner from physical, indirect, and nonverbal aggression, while females scored higher than males on being perpetrators of physical, indirect, nonverbal, and cyber aggression. The studies by Ndoromo et al. (2017) and Darko et al. (2018) support Archer's (2018) revised gender symmetry theory of intimate partner aggression but show that the theory holds not only in Western, but also in at least two African countries.

Types of intimate partner violence that were categorised as "patriarchal terrorism" and included severe physical and/or sexual violence have been found to be almost exclusively male perpetrated (Stark, 2007). Aggressive behaviours categorised as "common couple violence" which included less 
aggressive intimate partner violence such as pushing, slapping, hitting and verbal abuse were more gender symmetric. The prevalence rates of female perpetrated common couple violence in the subSaharan African ranges from about 25\% in South Africa (Gass, Stein, William, \& Seedat, 20I I) to 34\% in Kenya (Simister, 2010). In a study from Uganda, it was found that not only females, but also males had been victimised from intimate partner rape. Victimisation was linked to increased levels of negative psychological concomitants in both females and males (Nakyazze, Österman, \& Björkqvist, 2020). The current study includes measures of both males controlling females and females controlling males in relation to intimate partner rape. Female control over males is an understudied field which deserves more attention. Males as victims of intimate partner rape is likewise understudied. The present study aims at bridging this knowledge gap.

\section{Method}

\section{Participants}

A questionnaire was completed by 609 females and 420 males in Uganda. The age range was between 16 and 94 years. The mean age was 31.5 (SD 10.9) for females, and 34.4 (SD I I.3) for males, the age differences was significant $\left[t_{(1027)}=4.05, p<.00 I\right]$. The eligibility standards were the same for all participants. Participation was open to Ugandans above 16 years of age (except those living abroad) regardless of their background. Verbal consent was obtained before the questionnaire was handed to the participants. For the participants that felt uncomfortable after reading the questions, they had the right to withdraw participation.

\section{Instrument}

The questionnaire included scales for the measurement of frequency of victimisation from intimate partner rape, controlling behaviour, and physical aggression from an intimate partner.

The scale for measuring frequency of victimisation from intimate partner rape was adapted from Nakyazze, Österman and Björkqvist (2018). The scale was based on seven items and especially constructed for use in Uganda. The single items were as follows: Have you experienced the following from your present or previous partner? (a) Forced sex against your will when you were tired or ill, 


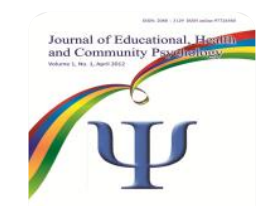

Journal of Educational, Health and

Community Psychology

Vol 11, No 1, 2022 E-ISSN 2460-8467
Nakyazze,

Österman,

Björkqvist.

(b) Forced by a partner into unwanted sexual acts, (c) Forced sex after physical assault, (d) A partner has put his/her arms around your neck trying to choke you in order to forcefully have sex with you, (e) A partner has raped you after giving you alcohol or drugs, (f) A partner has threatened to hurt you with an object or a weapon in order to have sex with you, and (g) A partner has raped you using an object. Cronbach's Alpha for the scale was .93.

Victimisation from controlling behaviour by an intimate partner were measured with seven items adapted from Graham-Kevan (2004). The single items were: (a) Limited the number of activities you can engage in outside the relationship, (b) Restricted the time you spend with your own friends and/or family, (c) Wanted to know everywhere you go and with whom you speak, (d) Been jealous of you and therefore monitored your activities, (e) Not let you use money that belongs to both of you, (f) Disapproved of you working or studying, and (g) Decided how you should dress. Cronbach's Alpha for the scale was .92 .

Victimisation from physical aggression from an intimate partner were measured with an abbreviated version of the Direct Indirect Aggression Scales for Adults (DIAS-Adult, Österman, \& Björkqvist, 2009). The seven items were as follows: (a) Hit you, (b) Locked you in, (c) Locked you out, (d) Shoved you, (e) Thrown objects at you, (f) Intentionally damaged something that was yours, and (g) Hit you with an object. Cronbach's Alpha for the scale was .96 .

The response alternatives for all three scales were on a five-point scale $(0=$ never, $\mathrm{I}=$ seldom, $2=$ sometimes, $3=$ often, $4=$ very often). The validity of the instruments is assured based on both comparisons with previous instruments of similar type, and the experience of the Ugandan culture that the first author possesses. The instruments were meticulously developed based on relevant previous research and consist of a collection of behaviours and indicators which together measure the intended concepts.

\section{Procedure}

A paper-and-pencil questionnaire was constructed and made available for distribution to the participants from December 2018 to December 2019. Most of the participants came in as patients 


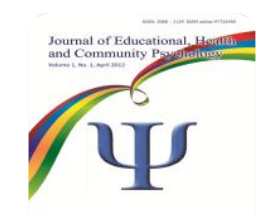

\section{Journal of Educational, Health and Community Psychology

to a healthcare clinic in Kalerwe which is a residential slum in Kampala. The questionnaires were also hand-delivered to participants in different urban and rural areas in Uganda.

\section{Ethical Considerations}

The study adheres to the principles concerning human research ethics of the Declaration of Helsinki adopted by the World Medical Association (2013), as well as guidelines for the responsible conduct of research of the Finnish Advisory Board on Research Integrity (20I2).

\section{Results}

\section{Correlations between the Scales}

For both females and males, victimisation from intimate partner rape was highly corelated with victimisation from intimate partner controlling behaviour and victimisation from intimate partner physical aggression (Table I). Victimisation from physical aggression and controlling behaviour from a partner were also highly correlated with each other for both females and males.

Table I

Correlations between Frequency of Victimisation from Intimate Partner Rape, Controlling Behaviour, and Physical Aggression from an Intimate Partner.

Females Below $(N=609)$ and Males Above the Diagonal $(N=420)$

\begin{tabular}{|c|c|c|c|}
\hline Victimisation from & I. & 2. & 3. \\
\hline I. Intimate Partner Rape & & $.40 * * *$ & $.69 * * *$ \\
\hline 2. Intimate Partner Controlling Behaviour & $.55 * * *$ & & $.53 * * *$ \\
\hline 3. Intimate Partner Physical Aggression & $.71 * * *$ & $.73 * * *$ & \\
\hline
\end{tabular}

Sex Differences in Victimization from Intimate Partner Rape

Sex differences in victimisation from intimate partner rape in the same sample as in the present study have previously been reported previously (Nakyazze, Österman, \& Björkqvist, 2020). Although women reported higher frequencies of victimisation from intimate partner rape than men, men did also report exposure to it. 


\section{Concomitants of Victimisation from Intimate Partner Rape}

A dichotomous variable was created for high vs. low victimisation from intimate partner rape. A multivariate analysis of variance (MANOVA) was conducted with victimisation from intimate partner rape (high/low), and sex as independent variables, victimisation from controlling behaviour and physical aggression from an intimate partner as dependent variables, and age as covariate. The multivariate analysis was significant for both sex and rape group (Table 2, Fig. I). The univariate analyses showed that females had been significantly more often victimised from intimate partner physical aggression than males. No significant difference was found between females and males on victimisation from intimate partner controlling behaviour. Respondents who had been more than average victimised from intimate partner rape scored significantly higher than others on victimisation from intimate partner controlling behaviour and intimate partner physical aggression.

Table 2

Results of a Multivariate Analysis of Variance (MANOVA) with Frequency of Victimisation from Intimate Partner Rape (High/Low) and Sex as Independent Variables, Victimisation from Controlling Behaviour and Physical Aggression from an Intimate Partner as Dependent Variables, and Age as Covariate ( $N=1029)$. Cf. Fig. I.

\begin{tabular}{|c|c|c|c|c|c|}
\hline & $F$ & $d f$ & $p \leq$ & $\eta_{p}^{2}$ & $\begin{array}{l}\text { Group with } \\
\text { Higher Mean }\end{array}$ \\
\hline Age as covariate & 7.68 & 2,1016 & .001 & .015 & \\
\hline Effect of Sex & & & & & \\
\hline Multivariate Analysis & 10.24 & 2,1016 & .001 & .020 & \\
\hline Univariate Analyses & & & & & \\
\hline $\begin{array}{l}\text { Intimate Partner Controlling Behaviour } \\
\text { Intimate Partner Physical Aggression }\end{array}$ & $\begin{array}{l}0.77 \\
18.10\end{array}$ & 1,1017 & $\begin{array}{l}n s \\
.001\end{array}$ & $\begin{array}{l}.001 \\
.017\end{array}$ & $\begin{array}{c}- \\
\text { Females }\end{array}$ \\
\hline Effect of Rape Group (High/Low) & & & & & \\
\hline Multivariate Analysis & 301.53 & 2,1016 & .001 & .372 & \\
\hline Univariate Analyses & & & & & \\
\hline Intimate Partner Controlling Behaviour & 221.86 & 1,1017 & .001 & .179 & High RG \\
\hline $\begin{array}{l}\text { Intimate Partner Physical Aggression } \\
\text { Interaction Effect }\end{array}$ & 596.82 & 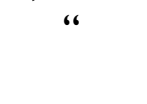 & .001 & .370 & High RG \\
\hline Multivariate Analysis & 0.02 & 2,1016 & ns & .000 & \\
\hline
\end{tabular}

Note. RG = Rape Group 

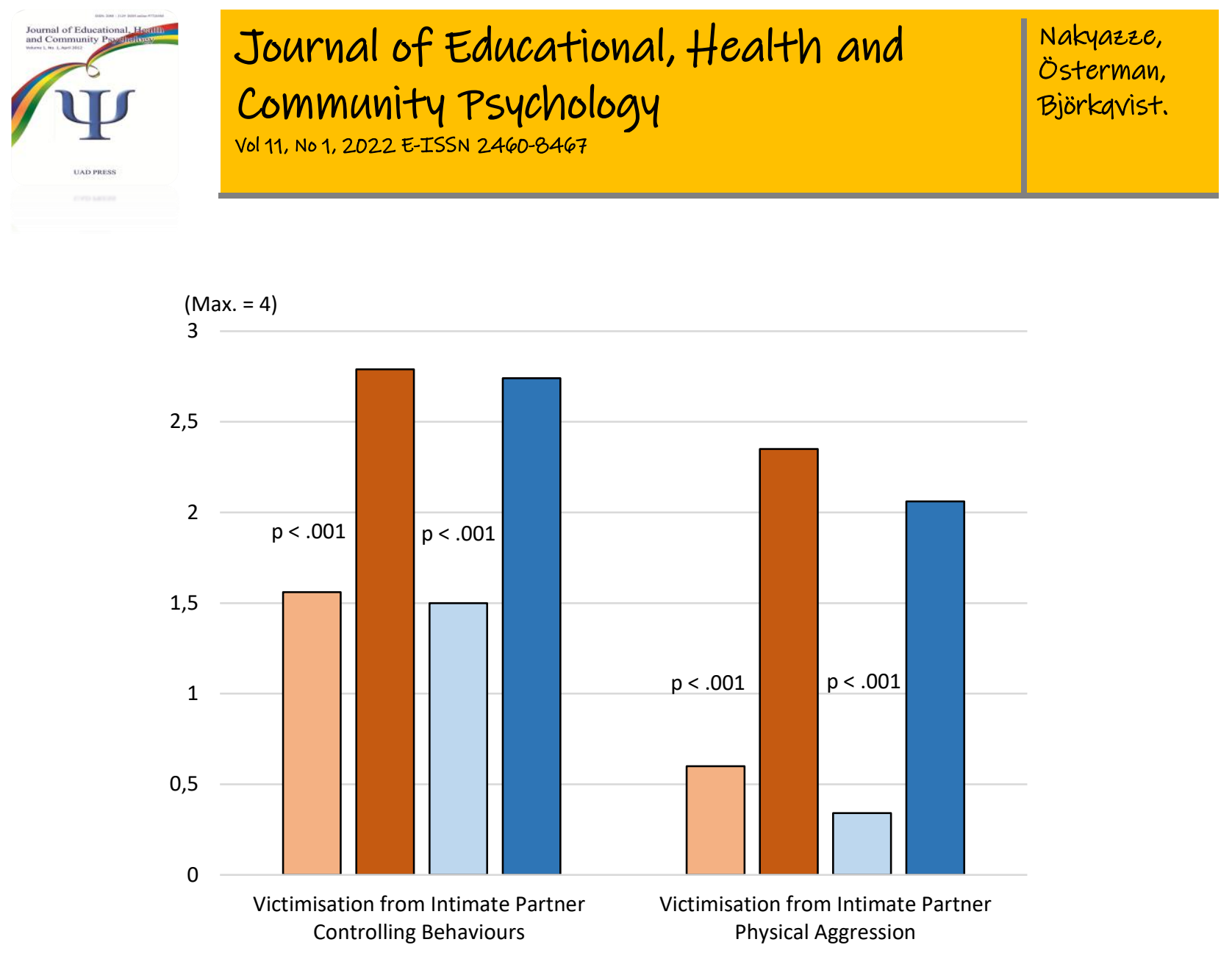

Level of Victimisation from Intimate Partner Rape

$\begin{array}{ll}\square \text { Females Low } & \square \text { Females High } \\ \square \text { Males Low } & \square \text { Males High }\end{array}$

Fig. 2. Mean values on victimisation from intimate partner controlling behaviour and victimisation from intimate partner physical aggression for females and males victimised from high vs. low levels of intimate partner rape $(N=1,029)$.

\section{Discussion}

Controlling behaviour can be categorised as a form of common couple aggression, because it is primarily not based on physical violence. In the present study, no significant difference was found between females and males on victimisation from intimate partner controlling behaviour. The finding is consistent with previous findings of common couple aggression being gender-symmetric (Stark, 2007). Controlling behaviour as measured in the present study may also be regarded as a form of low intensity intimate partner aggression (Darko et al., 2019; Ndoromo et al., 2018). The finding that no sex difference regarding controlling behaviour could be found in the current study provides support for the revised gender symmetry theory of intimate partner aggression (Archer, 20I8), and 


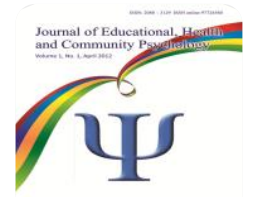

is additional evidence of the fact that it holds true also in African countries, as previously has been found by Ndoromo et al. (2017) and Darko et al. (2019).

Controlling behaviour has been considered important in its own right as well as a proxy for violence (Johnson, 2006). In the current study, it was found that respondents who had been more than average victimised from controlling behaviour scored significantly higher than others on victimisation from both intimate partner physical aggression and intimate partner rape. This is in line with previous research where different types of intimate partner abuse have been found to overlap (Johnson, 2006). In the present study, victimisation from controlling behaviour showed the same pattern for women and men, i.e. both were at a heightened risk for victimisation from both physical aggression and rape perpetrated by their partner. The finding can be viewed as consistent with findings of intimate partner sexual violence starting with controlling behaviour and later escalating to physical abuse (Sugarman \& Frankel, 1996). In the present study, this was the case for both women and men. It can be concluded that the association between victimisation from controlling behaviour and intimate partner physical aggression and rape followed the same pattern for females and males.

A previous study has reported that women, in the same sample from Uganda, as in the present study, were more often victimised from intimate partner rape than men (Nakyazze, Österman, \& Björkqvist, 2020). In many African societies, there is increased vulnerability and risk for intimate partner rape for women (Yodanis, 2004) since women are commodified and are often traded by their fathers for marriage (Ellsberg, Heise, Peña, Agurto, \& Winkvist, 200I). There is also a belief that women's sexual responses must be repressed, which leaves them at the mercy of their partners (Morrell, Jewkes, \& Lindegger, 2012). However, in the present study, men did also report exposure to intimate partner rape. The gender difference in victimisation from intimate partner rape (Nakyazze et al., 2020) might also be affected by self-reporting biases. Men might not be open to disclosing victimisation from intimate partner rape due to the need to save their reputation, since victimisation from partner rape rips them of their masculinity, and they might be judged negatively by society. In Uganda, many people find it hard to even believe that a man can be raped by a woman. In Africa, both men and women, especially in rural family settings, endorse the use of physical violence against partners as a disciplinary measure or a means of enforcing obedience (Koenig et al., 2003; Mann \& Takyi, 2009; Worden \& 


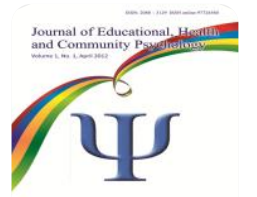

Carlson, 2005). Society tends to support physical violence especially against wives (Worden \& Carlson, 2005). Attitudes toward male perpetrated physical violence, especially in the context of marriage, have origins in the way women and girls are treated in Africa. In most communities, gender inequality begins at an early age for girls, when they are reduced to subordinated roles (Dobash \& Dobash, 1979). This circumstance leads to an amassed socialisation, and it is therefore not surprising that people in many African societies adopt to the patriarchal doctrines they have been exposed to from an early age (Dutton, 2006; Johnson, 1995). In sub-Saharan Africa, a considerable proportion of both men and women endorse "justified" abuse and find it a man's perquisite to physically discipline his wife when she neglects her wifely duties such as sexual ones, domestic chores, taking care of the children, and when she is disrespectful or tries to argue with her husband (Koenig et al., 2003). The patriarchal ideology is deeply embedded in most African cultures, and it is often equally endorsed by both men and women (Mann \& Takyi, 2009); therefore, any efforts to change this norm need to target both sexes.

\section{Limitations of the Study}

Most of the participants were from within the capital city of Kampala or its surrounding areas. The sample is therefore not a true representative of all men and women in Uganda; population samples with most participants from rural areas could have different outcomes from those taken in urban areas. Some "would have been participants" may not have been comfortable participating in the study because they found it to be very sensitive and a private matter, given the nature of African traditional norms, where intimate partner sexual violence is considered a bedroom matter that should never be discussed. Further still, although efforts were made to try and make the questions and the scales easy and straight forward in the questionnaire, participants often asked for meanings and clarification.

\section{References}

Anderson, K. L. (2008). Is partner violence worse in the context of control? Journal of Marriage and Family, 70, II57-II68.

Antai, D. (20II). Controlling behavior, power relations within intimate relationships and intimate partner physical and sexual violence against women in Nigeria. BMC Public Health, II, 5 I I. doi:|0.| | 86/|47|-2458-||-5I| 
Archer, J. (2000). Sex differences in aggression between heterosexual partners: A meta-analytic review. Psychological Bulletin, 126, 65I-680. doi:10.1037/0033-2909.126.5.65I

Archer, J. (2018). Violence to partners: Gender symmetry revisited. In J. L. Ireland, P. Birch, \& C. A. Ireland (Eds.), The Routledge international handbook of aggression: Current issues and perspectives (pp. 155-169). London, UK: Routledge.

Barshis, V. (1983). The question of marital rape. Women's Studies International Forum, 6, 383-393.

Bergen, R. K. (1996). Wife rape: Understanding the response of survivors and service providers. Thousand Oaks, CA: Sage.

Boakye, K. E. (2009). Attitudes toward rape and victims of rape: A test of the feminist theory in Ghana. Journal of Interpersonal Violence, 24, 1633-165I. doi:I0.1 I77/088626050933 I493

Bronfenbrenner, U. (1974). Developmental research, public policy, and the ecology of childhood. Child Development, 45, I-5. https://doi.org//0.2307/II 27743

Campbell, J. C. (1989). Women's response to sexual abuse in intimate relationships. Health Care for Women International, 10, 335-346.

Campbell, J. C., \& Soeken, K. L. (1999). Forced sex and intimate partner violence: Effects on women's risk and women's Health. Violence Against Women, 5, I0I7-1035. doi.org/I0.1I77/I07780I299005009003

Coker, A., Smith, P. H., McKeown, R. E., \& King, M. J. (2000). Frequency and correlates of intimate partner violence by type: Physical, sexual, and psychological battering. American Journal of Public Health, 90, 553-559. doi: 10.2105/AJPH.90.4.553

Darko, G., Björkqvist, K., \& Österman, K. (2019). Low intensity intimate partner aggression in Ghana: Support for the revised gender symmetry theory in an African country. Aggressive Behavior, 45, 52-61. doi:10.1002/ab.21796

Dobash, R. E., \& Dobash, R. P. (1979). Violence against wives: A case against the patriarchy. New York: Free Press.

Dutton, D. G. (2006). Rethinking domestic violence. Vancouver, Canada: UBC Press.

Ellsberg, M., Heise, L., Peña, R., Agurto, S., \& Winkvist, A. (200I). Researching domestic violence against women: Methodological and ethical considerations. Studies in Family Planning, 32, I16. doi:I0.1 III/j.1728-4465.2001.0000I.x

Fiebert, M. (1997). Annotated bibliography: References examining assaults by women on their spouses/partners. Sexuality and Culture, I, 273-286.

Finkelhor, D., \& Yllo, K. (1985). License to rape: Sexual abuse of wives. New York: Holt, Rinehart \& Winston.

Finnish Advisory Board on Research Integrity. (2012). Responsible conduct of research and procedures for handling allegations of misconduct in Finland. Helsinki, Finland.

Frieze, I. H. (1983). Investigating the causes and consequences of marital rape. Signs, 8, 532-553.

Gage, S., \& Hutchinson, P. (2006). Power, control, and intimate partner sexual violence in Haiti. Archives of Sexual Behavior, 35, II-26. doi: I0.1007/s 10508-006-899I-0

Galtung, J. (1990). Cultural violence. Journal of Peace Research, 27, 29I-305. doi:I0.1 I 77/0022343390027003005

Garcia-Moreno, C., Jansen, H. A., Ellsberg, M., Heise, L., \& Watts, C. H. (2006). Prevalence of intimate partner violence: Findings from the WHO multi-country study on women's health and domestic violence. Lancet, 368, 1260-1269. 
Gass, J. D., Stein, D. J., Williams, D. R., \& Seedat, S. (20I I). Gender differences in risk for intimate partner violence among South African adults. Journal of Interpersonal Violence, 26, 2764 2789. doi: I0.1I77/108862605I0390960

Goodmark, L. (20I I). A troubled marriage: Domestic violence and the legal system. New York: New York University Press.

Graham-Kevan, N. J. A. (2004). Physical aggression and controlling behaviours within relationships. Unpublished doctoral thesis. Preston, UK: University of Central Lancashire.

Heise, L., Ellsberg. M., \& Gottemoeller, M. (1999). Ending violence against women. Population Reports Series L, I I. Baltimore, MD: Johns Hopkins University School of Public Health.

Jenkin, S. R. (2000). Introduction to the special issue: Defining gender, relationships, and power. Sex Roles, 42, 467-493. doi:I0.1023/A:I0070I0604246

Jewkes, R., \& Morrell, R. (2010). Gender and sexuality: emerging perspectives from the heterosexual epidemic in South Africa and implications for HIV risk and prevention. Journal of the International AIDS Society, 13, 6. doi:10.1 I86/1758-2652-13-6

Johnson, M. P. (1995). Patriarchal terrorism and common couple violence: Two forms of violence against women. Journal of Marriage and the Family, 57, 283-294.

Johnson, M. P. (2000). Conflict and control: Images of symmetry and asymmetry in domestic violence. In A. Booth, A. Crouter, \& M. Clements (Eds.), Couples in conflict (pp. 178-204). Hillsdale, NJ: Lawrence Erlbaum.

Johnson, M. P. (2006). Conflict and control: Gender symmetry and asymmetry in domestic violence. Violence Against Women, I2, I003-1008. doi:I0.II 17//107780 I 206293328

Khan, M. E., Townsend, J. W., Sinha, R., \& Lakhanpal, S. (1996). Sexual violence within marriage. New Delhi, India: Population Council.

Koenig, M. A., Lutalo, T., Zhao, F., Nalugoda, F., Wabwire-Mangen, F., Kiwanuka, N., Wagman, J., Serwadda, D., Wawer, M., \& Gray, R. (2003). Domestic violence in rural Uganda: Evidence from a community-based study. Bulletin of the World Health Organization, 8I, 53-60.

Mahoney, P., \& Williams. L. M. (1998). Sexual assault in marriage: Prevalence, consequences, and treatment of wife rape. Durham, NH: Family Research Laboratory.

Mann, J. R., \& Takyi, B. K. (2009). Autonomy, dependence, or culture: Examining the impact of resources and socio-cultural processes on attitudes towards intimate partner violence in Ghana, Africa. Journal of Family Violence, 24, 323-335. doi: I 0.1007/s I 0896-009-9232-9

Morrell, R., Jewkes, R., \& Lindegger, G. (20I2). Hegemonic masculinity/masculinities in South Africa: Culture, power, and gender politics. Men and Masculinities, 15, II-30. doi: I0.1 I77/1097/84X 1243800 I

Nakyazze, B., Österman, K., \& Björkqvist, K. (2018). Sexual abuse and accepting attitudes towards intimate partner rape in Uganda. Medical Science and Discovery, 5, 21 I-219. doi: $10.17546 / \mathrm{msd}$

Nakyazze, B., Österman, K., \& Björkqvist, K. (2020). Victimisation from intimate partner rape in Uganda: Sex differences, psychological concomitants, and the effect of educational level. Medical Science and Discovery, 7, 603-610.

National sex and reproduction research team., \& Jenkins, C. (1994). National study of sexual and reproductive knowledge and behaviour in Papua New Guinea (PNG). Goroka, Guinea: PNG Institute of Medical Research. 
Ndoromo, O., Österman, K., \& Björkqvist, K. (20I7). Domestic violence as a risk factor for children ending up sleeping in the streets of post-war South Sudan. Journal of Child and Adolescent Behaviour, 5, I. doi:10.4172/2375-4494.100033

Österman, K., \& Björkqvist K. (2009). Direct Indirect Aggression Scales for Adults (DIAS-Adult). Vasa, Finland: Åbo Akademi University.

Pagelow, M. D. (198I). Woman-battering: Victims and their experiences. Beverly Hills, CA: Sage.

Pence, E., \& Paymar, M. (1993). Education groups for men who batter: The Duluth Model. New York: Springer.

Próspero, M., Dwumah, P., \& Ofori-Dua, K. (2009)._Violent attitudes and mental health symptoms among mutually violent Ghanaian couples. Journal of Aggression, Conflict and Peace Research, I, 16-23. doi:10.1 108/17596599200900009

Reitzel-Jaffe, D., \& Wolfe, D. A. (200I). Predictors of relationship abuse among young men. Journal of Interpersonal Violence, 16, 99-II5. doi:10.1 I77/08862600101600200 I

Rennison, C. M., \& Welchans, S. (2000). Intimate partner violence (Special report). Washington, DC: U.S. Bureau of Justice Statistics, National Institute of Justice.

Rozée, P. D. (1993). Forbidden or forgiven?: Rape in cross-cultural perspective. Psychology of Women Quarterly, I7, 499-5 I4. doi:I0.1 I II/j.147I-6402.1993.tb00658

Russell, D.E. H. (1990). Rape in marriage. New York: Macmillan Press.

Simister, J. G. (2010). Domestic violence and female genital mutilation in Kenya: Effects of ethnicity and education. Journal of Family Violence, 25, 247-257. doi:10.1007/s I0896-0099288-6

Stark, E. (2007). Coercive control: How men entrap women in personal life. New York: Oxford University Press.

Steinmetz, S. K. (1977-78). The battered husband syndrome. Victimology, 2, 499-509.

Straus, M. A. (2010). Thirty years of denying the evidence on gender symmetry in partner violence: Implications for prevention and treatment. Partner Abuse, I, 332-362. doi: 10.1891/1946-6560.1.3.33210

Straus, M. A., \& Ramirez, I. L. (2007). Gender symmetry in prevalence, severity, and chronicity of physical aggression against dating partners by university students in Mexico and USA. Aggressive Behavior, 33, 28I-290. doi:I0.1002/ab.2019910.1002/ab.20199

Sugarman, D. B., \& Frankel, S. L. (1996). Patriarchal ideology and wife-assault: A meta-analytic review. Journal of Family Violence, II, I3-40. doi: I0.1007/BF02333338

Tjadens, P., \& Thoennes, N. (2000). Prevalence, incidence, and consequences of violence against women: Findings from the National Violence against Women Survey. Washington, DC: U.S. National Institute of Justice, U.S. Department of Health and Human Services, and Centers for Disease Control and Prevention.

UNDP. (2013). Human development report 2013. The rise of the south: Human progress in a diverse world. New York. http://hdr.undp.org/en/content/human-development-report-20I3.

Weiss, E., \& Gupta, G. R. (1998). Bridging the gap: Addressing gender and sexuality in HIV prevention. Washington DC: International Center for Research on Women.

Williams, C. M., Larsen, U., \& McCloskey, L. A. (2008). Intimate partner violence and women's contraceptive use. Violence Against Women, 14, I382-1396. doi:10.1 I77/107780 I208325 I87

Worden, A. P., \& Carlson, B. E. (2005). Attitudes and beliefs about domestic violence: Results of a public opinion survey II: Beliefs about causes. Journal of Interpersonal Violence, 20, 1219|243. doi: | 0. I |77/088626050527853 | 


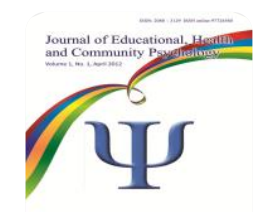

\section{Journal of Educational, Health and Community Psychology

World Medical Association (2013). Declaration of Helsinki: Ethical principles for medical research involving human subjects. JAMA, 310, 2191-2194.

Yodanis, C. L. (2004). Gender inequality, violence against women, and fear: A cross-national test of the feminist theory of violence against women. Journal of Interpersonal Violence, 19, 655675. doi: $10.1177 / 0886260504263868$. 